\title{
A Redução da Maioridade Penal: Questões Teóricas e Empíricas
}

Reduction of full legal age: Theoretical and empiric issues

Paula Inez Cunha

Faculdade Evangélica do

Paraná

Raphaella Ropelato

Centro Universitário

Positivo

Marina Pires Alves

Sociedade Paranaense de

Psicodrama

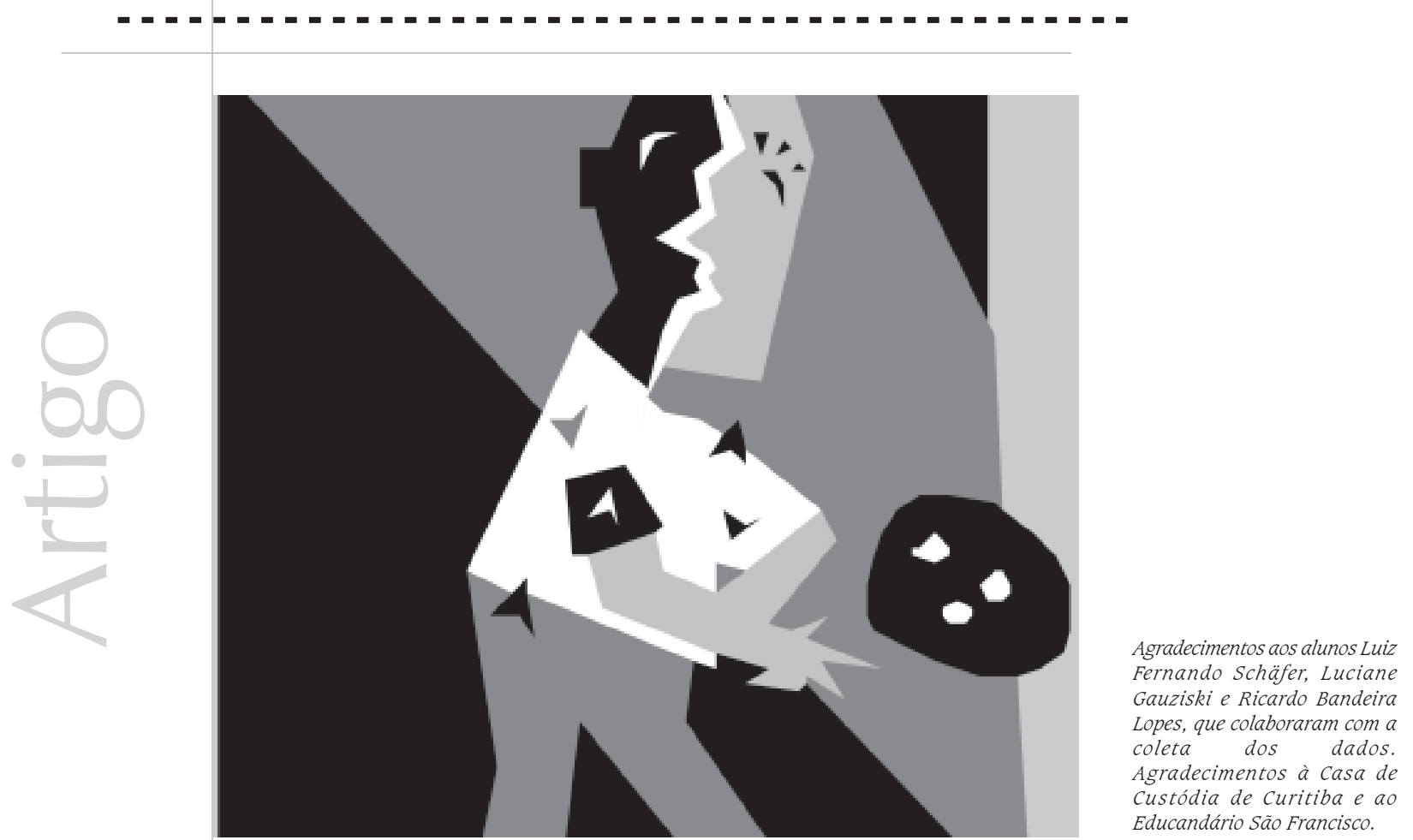




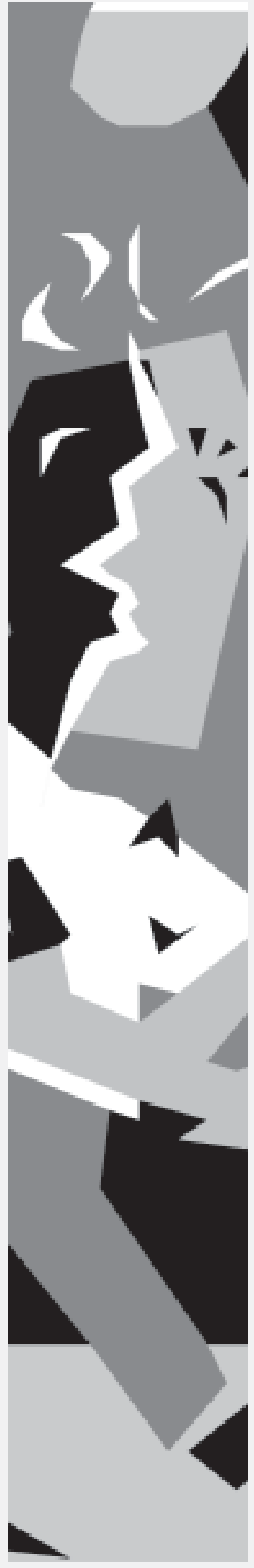

Resumo: As teses a favor e contra a redução da maioridade penal são debatidas neste estudo. Por um lado, políticos a favor da redução da maioridade penal argumentam que menores com 16 anos, quando constatado seu amadurecimento intelectual e emocional, devem ser responsabilizados penalmente; por outro lado, profissionais do Direito e da área social que lidam diretamente com crianças e adolescentes em situação de risco defendem a legislação atual, por entenderem que as medidas socioeducativas do ECA permitem a reeducação do adolescente em conflito com a Lei. Os dados, levantados por meio dos prontuários de 669 adolescentes internos no Educandário São Francisco (PR) e de 356 adultos da Casa de Custódia de Curitiba, indicaram uma correlação positiva $(r=0,071 ; p=0,05)$ entre gravidade dos delitos e idade. A idade é um fator que varia positivamente em relação à gravidade do delito, ou seja, quanto maior a idade, mais grave o delito. Essa informação apóia a política estabelecida pelo Estatuto da Criança e do Adolescente, que salienta que o adolescente é um ser em desenvolvimento e que, nesse sentido, deve ser submetido às medidas socioeducativas.

Palavras-chave: maioridade penal, periculosidade, adolescente em situação de risco.

Abstract: Theses which are for and against the reduction of full legal age are under debate in this study. On the one hand, politicians in favour of the reduction claim that minors under the age of 16 , once considered intellectually and emotionally mature, must respond legally for their acts. On the other hand, law professionals and social assistants who deal directly with target children and adolescents defend the present legislation, since they understand that the ECA social-educational measures permit the reeducation of the adolescents in conflict with the law. The data, collected from documents of 669 adolescents from the Educandário São Francisco (PR) and 356 adults from the Casa de Custódia de Curitiba, showed that there is a positive relation between the gravity of the crimes and age $(r=$ $0,071 ; p=0,05)$. Age is a variable that positively varies if related to the seriousness of the crime, so, the older the subject, more serious the crime. This information supports the policy established by the Child and Adolescent Statute, that emphasizes the fact that the adolescent is in continuous development and in that sense must be submitted to social and educational penalties.

Key words: reduction of full legal age, perilousness, risk adolescent. 
Poucos temas produzem tanta unanimidade e preocupação como a violência social. Cidadãos, cientistas, governantes, políticos, juízes, promotores, criminalistas, todos percebem e sofrem com o aumento da violência no País. Discutem-se meios para debelar ou, ao menos, diminuir a violência instalada em nosso meio social. É no campo das idéias e das alternativas para diminuir a violência social que surge a tese da redução da maioridade penal. Essa tese produziu reações contrárias dos defensores do Estatuto da Criança e do Adolescente (ECA), que propõem uma política educacional e não punitiva para o adolescente em conflito com a Lei. Este trabalho pretende discutir os argumentos a favor e contra a redução da maioridade penal, os determinantes comportamentais ligados ao desenvolvimento do comportamento anti-social e apresentar uma comparação entre a gravidade de delitos cometidos por adolescentes e adultos infratores.

Essa temática está circunscrita a de uma área da Psicologia denominada Psicologia jurídica, que, embora antiga em sua prática, apenas recentemente foi identificada como uma área de atuação e investigação psicológicas. Segundo o que determina o Conselho Federal de Psicologia (2001), o psicólogo pode atuar no âmbito da Justiça realizando pesquisa voltada à construção e ampliação do conhecimento psicológico aplicado ao campo do Direito. É nessa perspectiva que “...fornece subsídios ao processo judicial, além de contribuir para a formulação, revisão e interpretação das leis"; os especialistas da Psicologia Jurídica atuam também "...em pesquisas e programas socioeducativos e de prevenção à violência, construindo ou adaptando instrumentos de investigação psicológica, para atender às necessidades de crianças e adolescentes em situação de risco, abandonados ou infratores" (p.11).

\section{A favor da redução da maioridade penal}

Tramitam atualmente no Senado Federal três PECs (Propostas de Emenda à Constituição) que propõem a redução da maioridade penal de dezoito para dezesseis anos de idade. A PEC n.o 18, de 25/03/1999, de autoria do Senador Romero Jucá, pretende a alteração da redação do art. 228 da Constituição Federal, dando-lhe a seguinte forma: "Nos casos de crimes contra a vida ou o patrimônio, cometidos com violência, ou grave ameaça à pessoa, são penalmente inimputáveis apenas os menores de dezesseis anos, sujeitos às normas da legislação especial". Já a PEC n.o 20, de 25/03/1999 e a PEC n.o 3, de 22/03/ 2001, de autoria do Senador José Roberto Arruda, propõem a alteração do art. 228 da Constituição Federal no mesmo sentido, com o seguinte texto: "Os menores de dezoito anos e maiores de dezesseis anos são penalmente imputáveis quando constatado seu amadurecimento intelectual e emocional, na forma da lei (NR)".

O Senador Almir Lando (Agência do Senado, 2003), relator da Proposta, ao defender a PEC n. 3, afirma que os menores são plenamente conscientes de seus atos e que a atual Lei ignora suas características, protegendo-os das conseqüências de seus atos. Em outra proposta, o Senador Lando se manifesta favoravelmente à Proposta de Emenda à Constituição de autoria do ex-Senador Iris Rezende. Tal Proposta determina que menores de 18 anos e maiores de 16 devam responder por crime hediondo ou contra a vida, desde que haja laudo técnico definindo que o agente, na época do crime, teria condições de entender a transgressão que cometeu. Lando também é relator do Projeto de Lei do exSenador Carlos Wilson, que aumenta em um terço a pena de quem comete crime com a participação de adolescente com menos de 18 anos: "a matéria é muito pertinente, pois marginais têm utilizado menores para a 
execução dos crimes contando com sua inimputabilidade penal, o que contribui dramaticamente para a corrupção de nossa juventude", diz ele.

Borring (2003) afirma que existe certa relação da violência com o progresso do mundo e o amadurecimento mais precoce das crianças, sendo cabível a redução da maioridade penal. Afirma que a periculosidade dos delitos pelos adolescentes é a mesma dos delitos cometidos pelos adultos. Para o autor, o Código Penal brasileiro está atrasado em relação ao de outros países. Os Códigos Penais português (art. 19), cubano (art. 16), chileno (art. 10, $2^{\circ}$ ) e boliviano (art. $5^{\circ}$ ) fixam em 16 anos o início da responsabilidade penal. Os Códigos Penais russo (art. 16) e chinês (art. 14) fixam a maioridade penal em 16 anos, mas reduzemna para 14 anos nos delitos de homicídio, lesões graves, roubos e outros crimes de igual relevância. O Código Penal da Etiópia (art. 53) prevê o início da responsabilidade penal aos 15 anos. Uma outra argumentação citada por Saraiva (2002) e que é comumente utilizada a favor da redução da maioridade penal é o fato de o adolescente com 16 anos poder votar, o que poderia, então, justificar uma prisão com a mesma idade. Por outro lado, de acordo com Neto (1998), embora muitos países tenham reduzido a maioridade penal para dezesseis anos e até quatorze anos, $50 \%$ dos países ainda têm 18 anos como idade de responsabilização penal.

\section{Contra a redução da maioridade penal}

No tempo em que, cada vez mais, se tenta reduzir a maioridade penal, é importante que sejam revistas as considerações contrárias defendidas pelos profissionais que lidam com a questão no dia a dia. A Constituição da República define, em seu art. 228, que a pessoa com até 18 anos incompletos é penalmente inimputável, porém responsável por seus atos. São garantias, já que nenhum princípio do direito penal ou outro tipo de legislação pode se sobrepor à Constituição ou alterá-la.

Cuneo (2001) afirma que, em função de os adolescentes estarem em desenvolvimento e amadurecimento físico, emocional e psicológico, devem ser submetidos a medidas profiláticas que mantenham o convívio social e familiar. O autor apresenta levantamentos realizados no Brasil cujos resultados revelam que os crimes praticados por maiores de 18 anos representam mais de $90 \%$ do total de crimes cometidos, portanto, os adolescentes estariam praticando apenas 10\% das infrações. Em recente levantamento nacional, o Ministério da Justiça e o IPEA (2002) mapearam a situação do atendimento dos adolescentes em cumprimento de medidas socioeducativas em privação de liberdade, e encontraram 9.555 jovens internados em 190 instituições disponíveis, para esse fim, no País. No Brasil, para cada grupo de dez mil adolescentes, existem apenas três $(2,88 \%)$ jovens privados de liberdade. A proporção de adolescentes infratores do Estado do Paraná é de 1,9\% em relação à população de adultos; essa média é inferior à média nacional, que é de 2,88\%.

Ao contrário do que muitos pensam, imputabilidade não é sinônimo de impunidade. Neto e Grillo (1995) afirmam que "as medidas socioeducativas têm natureza e finalidades diferentes das penas previstas pelo código penal" (p. 78), pois pretendem garantir a manutenção do vínculo familiar associada ao caráter pedagógico apropriado a cada medida (v. arts. $112 \S 1^{\circ}, 113$ e 100. ECA)." Para efeito do ECA, aplica-se a medida de internação aos adolescentes autores de atos infracionais cometidos mediante grave ameaça ou violência contra pessoa ou pela reiteração no cometimento de outras infrações graves. As medidas socioeducativas do ECA são: advertência; obrigação de reparar o dano; prestação de serviços à comunidade; liberdade assistida; inserção em regime de semi- 
liberdade; internação em estabelecimento educacional. Sanson (1999) enfatiza que “... leva-se em consideração a natureza do ato infracional bem como a personalidade e as necessidades do infrator, de sorte que, pela prática de fatos idênticos, adolescentes podem receber medidas diversas (p. 108)". Os problemas de maus-tratos, violência familiar, abusos físico e sexual, uso de drogas podem alterar a determinação das medidas socioeducativas pelo juiz, Por esses fatos, diz o autor, é que a família do adolescente também precisa ser atendida, e que a medida socioeducativa adequada deve ser uma medida de proteção tanto à família quanto ao adolescente.

A maioria dos adolescentes que cometem atos infracionais encontra-se ainda em fase de socialização ou instrução.
A maioria dos adolescentes que cometem atos infracionais encontra-se ainda em fase de socialização ou instrução. O processo de reajustamento do adolescente infrator, portanto, deve ser submetido à educação, ainda que em unidade socioeducativa de internamento, e não à pena criminal, muito embora, como apontam a pesquisa do Ministério da Justiça e o IPEA (2002), ainda $71 \%$ dos ambientes físicos das unidades de internamento do País estão em condições inadequadas para fazer cumprir as medidas socioeducativas, o que requer um investimento sério do poder publico para a adequação das unidades de internação aos preceitos defendidos pelo ECA. Por outro lado, $99 \%$ das unidades oferecem educação escolar em ensino fundamental e $63 \%$ em ensino médio, além de oportunizarem profissionalização em $85 \%$ das mesmas.

A Subcomissão da Criança e do AdolescentePR (1995), em entrevista a 13 parcelas da população paranaense, obteve como dado que $62 \%$ das pessoas pensam que crianças e adolescentes deveriam estar em escolas, em suas casas ou em atividades culturais, esportivas e de lazer, e que, se estão nas ruas, é porque não tiveram acesso a essas atividades. Concluem os pesquisadores que essa opinião "é um bom indicador de que a sociedade está sensível a propostas de criação de programas comunitários, inseridos no meio social, para população carente" (p.42).

Dessa maneira, o argumento sustentado pelos favoráveis à redução da maioridade penal que têm o apoio da população para a mudança da Lei é discutível. A Andi - Agência de Notícias dos Direitos da Infância (1999) - chama a atenção para a inadequação metodológica da pesquisa de opinião feita com o intuito de avaliar o apoio da população a essa iniciativa. A pergunta "O adolescente de 16 anos deve ser responsabilizado criminalmente?" induz a uma resposta afirmativa. Além disso, deve-se deixar claro que os projetos de lei para a redução da maioridade penal estabelecem que esses adolescentes sejam levados ao sistema carcerário destinado aos adultos que, atualmente, apresenta um déficit de 87.025 vagas e nunca foi avaliado.

\section{Ser em desenvolvimento}

A tese do ser humano em desenvolvimento embasa a posição dos principais defensores do uso de medidas socioeducativas em lugar de medidas punitivas. Em que se sustenta essa tese, em termos psicológicos? Cientistas comportamentais (Conte, 1996; Feldman, 1977; Gomide, 2004; Kasdin e Buela-Casal, 1977; Montagu, 1988; Nurco e Lerner, 1996; Patterson, Reid e Dishion, 1992; Sidman, 1995) têm enfatizado a correlação entre práticas parentais e desenvolvimento de comportamento anti-social. Estudos recentes destacam que práticas parentais negativas propiciam o aparecimento de comportamentos anti-sociais ou infratores (Prust e Gomide (a), no prelo; Prust e Gomide (b), no prelo; Berri, 2004; Pinheiro, 2003; Carvalho e Gomide, 2005), além de indicarem uma correlação positiva entre as práticas parentais positivas e habilidades sociais e correlação negativa entre praticas parentais positivas e depressão e stress (Gomide, Salvo, Pinheiro e Sabbag, 2005). 
Essas práticas negativas, por um lado, são basicamente caracterizadas pelo uso da punição física como forma de disciplinar, pela negligência, que pode ser afetiva, econômica, educacional ou da saúde do filho, pelos abusos psicológicos, em que as ameaças de abandono e xingamentos fazem a rotina das relações familiares e pelos abusos sexuais, que estão ligados ao histórico de vida dos infratores de maior periculosidade. Por outro lado, encontrase a ausência das práticas parentais positivas nas famílias em risco social, que são aquelas mediadas pelo afeto, pela empatia, pelo amor, pelo acompanhamento cuidadoso, em que os pais ensinam o certo e o errado, praticam as virtudes e fornecem exemplos com coerência (Araújo, 1999; Kurtines e Gewirtz, 1991; La Taille, 2004; Conte-Sponville, 2000).

Mesmo aceitando que existe uma predisposição biológica, observada em crianças com temperamento difícil, que dificultam o relacionamento familiar e, muitas vezes, afastam os pais da tarefa educativa, Patterson e colaboradores (1992) indicam que a maneira como os pais educam, com maior afeto, acompanhamento, exemplos morais, ausência de abusos físicos, psicológicos ou sexuais determina o desenvolvimento ajustado e saudável da criança e do adolescente. Nessa perspectiva teórica, os déficits de condições habitacionais, de saúde e de trabalho contribuem fortemente para instalar relações negativas entre pais e filhos. Essa situação social de risco favorece o desenvolvimento das práticas parentais negativas, ou seja, pais desempregados, sem condições de sustentar os filhos, estão mais irritadiços, mais agressivos, menos compreensivos e menos presentes. Esses fatores tornam prevalentes os relacionamentos familiares que permitem o aparecimento de comportamentos anti-sociais, como o uso de punição e ameaça para disciplinar o filho.

A ciência comportamental ressalta que a melhor maneira de se desenvolver comportamentos pró-sociais ou de se inverter as tendências ou práticas infratoras está em implementar programas educativos que envolvam os pais e os próprios adolescentes ou crianças. O objetivo desse procedimento é propiciar a identificação das práticas educativas parentais inadequadas e incrementar aquelas capazes de facilitar o aparecimento de comportamentos adaptativos e sociais. Todo programa de recuperação de adolescente ou criança que cometem atos anti-sociais deve envolver atividades pedagógicas, de lazer e terapêuticas, que busquem elevar a auto-estima da clientela e os insira em atividades escolares, profissionais e familiares com apoio, de forma a evitar fracassos e facilitar o sucesso do adolescente em tais atividades (Conte, 1996; Feldman, 1977; Gomide, 1998, 2003, Berri, 2004).

Os pesquisadores brasileiros, nas décadas de 1980 e 1990, demonstraram o fracasso das instituições totais e daquelas destinadas ao atendimento de adolescentes infratores (Altoé, 1985; Arruda, 1983; Baeta, 1982; Bierrembach, Sader e Figueiredo, 1987; Campos, 1981; Edmundo, 1987; Gomide, 1998; Luppi, 1987; Pinheiro, 1985; Ribeiro e Barbosa, 1987; Rizzini, 1985; Rocha, 1984; Silva, 1977; Silva, 1987; Villela, 1983; Violante, 1982). Os principais resultados, nesses estudos, mostraram que a instituição incrementa a identidade infratora, propicia o conhecimento da rede criminal (mocós, tráfego, mandantes, corrupção policial, acesso a armas, etc.), aumenta a discriminação social, diminui as possibilidades de inserção no trabalho e na escola, aumenta o hedonismo e o determinismo. Em resumo, esses estudiosos concluíram que as instituições aumentavam as habilidades infratoras dos adolescentes que lá foram internados. Deve-se lembrar que as instituições analisadas, embora destinadas a crianças e adolescentes, eram retrato da política de internamento e retirada do meio social prescrita no Código de Menores. O ECA estabelece uma forma alternativa e pedagógica
A ciência comportamental ressalta que a melhor maneira de se desenvolver comportamentos pró-sociais ou de se inverter as tendências ou práticas infratoras está em implementar programas educativos que envolvam os pais e os próprios adolescentes ou crianças. 
de lidar com adolescentes autores de ato infracional, respeitando as principais teorias psicológicas que estudam o comportamento anti-social. O simples aprisionamento não possui caráter educativo; isso significa que apenas encarcerar não é medida capaz de evitar que o adolescente pratique crimes futuros.

Embora a sociedade deseje a punição do infrator, ela também espera que, ao sair da prisão, ele deixe de cometer atos infracionais. Se o sistema penal atende à primeira necessidade social, não atende à segunda. $\mathrm{O}$ investimento e a reestruturação das instituições criadas para executar as medidas socioeducativas do ECA poderão ser o caminho para o atendimento às duas demandas sociais. $\mathrm{O}$ adolescente é punido ao ser internado e retirado do meio social e, paralelamente, é submetido a programas que privilegiem sua re-inserção social por meio de atividades pedagógicas e de preparação para o trabalho.

\section{Objetivo do estudo}

Este estudo pretende discutir os argumentos a favor e contra a redução da maioridade penal, os determinantes comportamentais ligados ao desenvolvimento do comportamento anti-social e apresentar uma comparação entre a gravidade de delitos cometidos por adolescentes em conflito com a Lei e adultos autores de atos infracionais em unidades socioeducativas de internação e instituições prisionais estaduais de Curitiba.

\section{Método}

Prontuários: Foram consultados 1.025 prontuários, sendo 669 de adolescentes internos no Educandário São Francisco (PR) que cumpriam medida socioeducativa de internação e 356 de adultos infratores internados na Casa de Custódia de Curitiba. As idades variaram de 13 a 62 anos. Por meio dos prontuários, foram levantados os delitos/ crimes praticados pelo indivíduo bem como a idade de cada um.

Instrumentos: Ficha com os delitos/crimes obtidos por meio dos prontuários. Essa ficha foi entregue a profissionais do Direito (juízes, promotores e advogados criminalistas) para que atribuíssem, a cada delito, um grau de periculosidade, com nota igual a 1 para os delitos considerados leves, 2, para os moderados e 3, para os graves. Uma média ponderada das avaliações obtidas foi calculada para cada delito.

Procedimento: Após a permissão dos diretores das instituições, solicitou-se à seção de informática das unidades que emitisse uma listagem com a idade e o registro dos delitos dos internos. A ficha com a relação dos delitos foi entregue pessoalmente aos profissionais de Direito para que atribuíssem a cada delito um grau de periculosidade (leve-moderado-grave). Os pesquisadores aguardaram no local o preenchimento da ficha. A média ponderada de cada delito foi calculada, e esses dados foram digitados em uma planilha no SPSS (Statistical Package for Social Science) para que as comparações entre os grupos fossem feitas.

\section{Resultados}

Os delitos foram categorizados em leves, moderados ou graves em função do entendimento jurídico de promotores, juízes e advogados criminalistas, para os delitos considerados leves, 2, para os moderados. Cada delito foi avaliado por dois juízes, dois promotores e um advogado criminalista e, após a apuração dos pontos, foi calculada a média que refletia a opinião dos cinco avaliadores. A tarefa de julgamento da gravidade do delito foi de difícil execução, segundo os avaliadores. Muito embora fossem pessoas de experiência na área, pois analisam processos diariamente, relataram que 
dependiam de outras informações (como as circunstâncias em que o delito foi cometido) para atribuir com segurança uma nota que refletisse a gravidade do delito.

Categorizar os delitos em leves, moderados ou graves não é uma tarefa fácil. A metodologia aqui utilizada certamente é passível de críticas, pois não incorpora as circunstâncias em que foram cometidos os delitos. No entanto, discutir cada caso para que uma avaliação mais criteriosa fosse feita não seria possível, diante do número de prontuários disponíveis para análise de dados (1025), de maneira que a opção de se recorrer a criminalistas experientes foi a que melhor atendeu a essa dificuldade. Optou-se, então, por trabalhar com a média ponderada para cada delito (por exemplo, art. $129=$ dois votos para "leve" e três votos para "moderado" $=(2 \mathrm{X} 1)+(3 \mathrm{X} 2)=8$; esse resultado foi dividido pelo número de avaliadores (8/5), obtendo-se, então, a média ponderada $=1,6$ ).

Apenas sete artigos obtiveram a unanimidade dos avaliadores quanto à gravidade do delito (19, $121,148,158,171,180,213)$. O art. 289 (moeda falsa) foi o que maior dispersão apresentou, ou seja, foi avaliado como leve pelos promotores, moderado pelo advogado, moderado por um juiz e grave por outro. Os delitos encontrados nesta pesquisa, de acordo com o código penal, estão especificados na Tabela 1.

Tabela 1. Tipos, freqüência e nível de gravidade dos delitos

\begin{tabular}{|l|l|l|l|l|}
\hline Artigo & Descrição & Adulto & Adolescente & Nível de gravidade \\
\hline 14 & Assoc. tráfico / crime de ent. & 53 & 25 & 2,8 \\
\hline 19 & Porte de arma & 0 & 21 & 2 \\
\hline 121 & Homicídio & 41 & 132 & 3 \\
\hline 129 & Lesão corporal & 5 & 17 & 1,6 \\
\hline 147 & Ameaça & 0 & 15 & 1,4 \\
\hline 148 & Seqüestro e cárcere privado & 3 & 9 & 3 \\
\hline 155 & Furto & 77 & 156 & 1,6 \\
\hline 157 & Roubo & 199 & 302 & 2,8 \\
\hline 158 & Extorsão & 4 & 6 & 3 \\
\hline 163 & Dano & 2 & 7 & 1,2 \\
\hline 171 & Estelionato & 9 & 0 & 2 \\
\hline 180 & Receptação & 24 & 0 & 2 \\
\hline 213 & Estupro & 4 & 16 & 3 \\
\hline 214 & Atentado ao pudor & 1 & 9 & 2,8 \\
\hline 288 & Quadrilha ou bando & 6 & 3 & 2,6 \\
\hline 289 & Moeda falsa & 1 & 0 & 1,8 \\
\hline 299 & Falsidade ideológica & 3 & 0 & 1,8 \\
\hline 304 & Uso de documento falso & 1 & 0 & 1,8 \\
\hline 311 & Adulteração de sinal & & & 1,6 \\
\hline & identificador de veículo automotor & 2 & 0 & \\
\hline
\end{tabular}

A Tabela 2 mostra a distribuição dos participantes em função da idade e do nível de delito. A amostra de 1.025 prontuários de presos foi constituída por 669 adolescentes, internos do Educandário São Francisco, entre os anos 2000 e 2002, e 356 adultos, internos da Casa de Custódia do Paraná, no ano 2002. 
Aplicada a correlação de Pearson, obteve-se um $r=0,071(p=0,024)$ significativo, ao nível de 0,05 , indicando uma correlação positiva entre idade e gravidade de delito. O teste de Tukey HSD mostrou que, como pode ser visto na tabela 3, o grupo de adolescentes de 13-15 anos difere do grupo dos adultos com idade acima de 22 anos quanto à gravidade dos delitos, mas não difere dos adolescentes de 16-18 anos e dos adultos de 19-21 anos.

O teste $t$ (de Student) para amostras independentes mostrou haver diferenças significativas para a comparação do grupo 1 (13 a 15 anos) com o grupo 4 (22 a 30 anos), em que se obteve valor de $t=-2,279(p=0,026)$, e para a comparação do grupo 1 com o grupo 5 (31-62) com $t=-2,509$ $(p=0,014)$, corroborando os resultados do Tukey HSD; mas acrescentou também uma diferença estatisticamente significativa na comparação do grupo 2 (16-18) com o grupo 4, com valor de $t=$ $2,029(p=0,043)$. Todas as diferenças foram significativas ao nível de 0,05.

Tabela 2. Caracterização da amostra quanto à idade e gravidade dos delitos

\begin{tabular}{|l|l|l|l|l|}
\hline nivel & Leve & Moderado & Grave & Total \\
\hline idade & $(1 ; 1,2$ e 1,4$)$ & $(1,6 ; 1,8$ e 2$)$ & $(2,6 ; 2,8$ e 3$)$ & \\
\hline $13-15$ & $5(10,2 \%)$ & $16(32,65 \%)$ & $28(57,14 \%)$ & 49 \\
\hline $16-18$ & $34(9,31 \%)$ & $78(21,36 \%)$ & $253(69,31 \%)$ & 365 \\
\hline $19-21$ & $50(14,28 \%)$ & $74(21,14 \%)$ & $226(64,57 \%)$ & 350 \\
\hline $22-30$ & $3(1,61 \%)$ & $49(26,34 \%)$ & $134(72,04 \%)$ & 186 \\
\hline $31-62$ & $0(0 \%)$ & $22(29,33 \%)$ & $53(70,66 \%)$ & 75 \\
\hline Total & 92 & 239 & 694 & 1025 \\
\hline
\end{tabular}

\section{Discussão}

A questão da redução da maioridade penal, veiculada pela mídia e defendida por alguns políticos (Senador Romero Jucá, Senador José Roberto Arruda, Senador Almir Lando), advogados (Borring, 2003) e jornalistas, baseiase na premissa que os crimes cometidos por adolescentes têm gravidade igual aos daqueles cometidos por adultos e, por conseguinte, deveriam ser tratados pelo mesmo sistema penal. Além disto, esses defensores da redução da faixa etária de 18 para 16 anos acreditam que os adolescentes se comportam como adultos no que diz respeito à gravidade dos delitos.

Os dados obtidos neste estudo indicam haver uma influência positiva da idade para a ocorrência dos delitos mais graves $(r=0,071$; $p=0,024)$, ou seja, quanto mais velhos, maior a gravidade do delito. O teste de Tukey e $t$ (de student) esclarecem que as diferenças se dão entre o grupo 1 e os grupos 4 e 5 . Isso pode ser melhor entendido observando-se os dados da tabela 2, que mostram que os adolescentes do grupo 1 (13 a 15 anos) apresentam a menor percentagem de delitos graves dentre todos os grupos, principalmente quando comparados com os adultos dos grupos 4 (22 a 30 anos) e 5 (31-62).

Tabela 3. Teste de Tukey HSD

\begin{tabular}{|l|l|l|l|}
\hline Idade & $\mathrm{n}$ & 1 & 2 \\
\hline Grupo 1(13-15) & 49 & 2,245 & \\
\hline Grupo 2 (16-18) & 350 & 2,329 & 2,329 \\
\hline Grupo 3(19-21) & 365 & 2,435 & 2,435 \\
\hline Grupo 4 (22-30) & 186 & & 2,495 \\
\hline Grupo 5 (31-62) & 75 & & 2,539 \\
\hline Significância & & 0,199 & 0,124 \\
\hline
\end{tabular}

Essas informações sugerem que se deve investir numa política de atendimento 
diferenciado para os adolescentes autores de atos infracionais, pois aqueles que se encontram no início da escalada da criminalidade devem merecer do governo e da sociedade um atendimento especializado e de caráter preventivo. Esse atendimento especializado está sendo discutido na área da Psicologia Jurídica, que sugere que os profissionais da Psicologia devem auxiliar os juizados na avaliação e assistência psicológica de adolescentes e seus familiares bem como assessorá-los no encaminhamento às terapias psicológicas, quando necessário.

Os dados obtidos neste estudo indicam que os adolescentes de 16-18 apresentaram delitos de igual gravidade aos dos adultos pesquisados. É importante lembrar que, embora a legislação indique os procedimentos que deveriam ser adotados pelas instituições de atendimento aos adolescentes infratores, são poucas as que já atendem a essas determinações (Ministério da Justiça \& IPEA, 2002). Caso a Lei estivesse sendo cumprida pelos governos estaduais no que diz respeito à reestruturação dessas instituições, poderíamos esperar resultados diferentes e promissores nesta pesquisa.

As pesquisas psicológicas na área do desenvolvimento do comportamento antisocial (Conte, 1996; Feldman, 1977; Gomide, 2003, Gomide, no prelo; Kasdin \& Buela-Casal, 1977; Montagu, 1988; Nurco \& Lerner, 1996; Patterson, Reid \& Dishion, 1992; Sidman, 1995) apontam a influência dos estilos parentais negativos como determinantes da infração em crianças e adolescentes. Os autores mostram que pais negligentes, que abusam fisicamente dos filhos, que deixam de supervisioná-los, acompanhá-los e de fornecer modelos morais apropriados têm alta probabilidade de terem filhos com comportamentos anti-sociais ou infratores. Por outro lado, em famílias cujos pais estão presentes, são afetuosos, praticam valores morais e supervisionam amorosamente os filhos, raramente são encontrados adolescentes com comportamentos antisociais. Isso significa que orientação, treinamento e terapia para pais e filhos que apresentam comportamento anti-social ou infrator são algumas das formas indicadas cientificamente para a solução desse problema. Certamente, apenas o encarceramento não seria capaz de produzir os efeitos positivos desejados.

Petraitis, Flay e Miller (1995), em sua revisão sobre as teorias que explicam o uso de substãncias psicotrópicas, assinalam a importância dos modelos normativos para a explicação e predição de tal conduta desviante. Os autores indicam a importância de aderir às normas sociais e valores morais como fator de proteção contra o uso de drogas e outras condutas anti-sociais e delitivas.

Para Formiga e Gouveia (2005), quando os adolescentes não se sentem envolvidos, comprometidos ou são, mesmo, alijados da sociedade convencional, da escola, da religião, não serão capazes de internalizar os valores ou padrões convencionais e de se comportar segundo as normas sociais vigentes. Contrariamente, quando estes assumem a importância dos papéis convencionais, são encorajados a apresentar comportamentos convencionais e a se opor a condutas desviantes.

Alguns autores (Coelho Junior, 2001; Romero, Sobral, Luego \& Marzoa, 2001; Tamayo, Nicaretta, Ribeiro \& Barbosa, 1995) vêm observando que a adesão a valores mais pessoais - enfatizando o individualismo promove o uso de drogas, a amizade com jovens delinqüentes e as dificuldades na aprendizagem, enquanto a adesão a valores 
Os resultados deste estudo mostraram que a idade é um fator que varia positivamente em relação à gravidade do delito, ou seja, quanto maior a idade, mais grave o delito. sociais - ênfase coletivista - promoveria fatores de proteção, de maneira que os valores humanos têm sido considerados um dos principais construtos teóricos capazes de prevenir o desenvolvimento de comportamentos antisociais. É importante deixar claro que, ao se falar de valores humanos ou virtudes, fala-se de uma crença duradoura bem como de uma maneira de se comportar, que pode ser preferida no âmbito pessoal e social (Gusmão et al.)

A identidade infratora é caracterizada pelo hedonismo, em que o comportamento é definido pelo prazer imediato e pelo determinismo, o que coloca um futuro breve e com desfecho trágico para os adolescentes infratores (Gomide, 1998). As unidades de atendimento de crianças e adolescentes de risco devem desenvolver prioritariamente atividades que aumentem a auto-estima do seu educando, uma vez que a literatura enfatiza que a auto-estima elevada é um dos principais antídotos ao aparecimento ou à manutenção do comportamento infrator (Feldman, 1977; Gomide, 1998). Essas atividades estão ligadas ao bom desempenho escolar, à realização de atividades profissionais significativas e relevantes, ou, ainda, à harmonia dos relacionamentos interpessoais, seja com a família, seja com os amigos, seja com a própria equipe de educadores.

\section{Conclusão}

O entendimento de que a gravidade do crime acontece em função das experiências vividas em gangs e na rotina do crime é que justifica um atendimento especial oferecido pelo ECA a partir de medidas socioeducativas. A política do ECA é de reabilitação com características não punitivas. Essa atitude diferencia fortemente as duas correntes de pensamento. Por um lado, o ECA estabelece uma política educacional que visa a reinserção do adolescente infrator ao meio social; por outro, o código penal preconiza que o infrator deve receber pena, considerada estratégia suficiente para inibir o crime futuro.

Os resultados deste estudo mostraram que a idade é um fator que varia positivamente em relação à gravidade do delito, ou seja, quanto maior a idade, mais grave o delito. Essa informação apóia a política estabelecida pelo Estatuto da Criança e do Adolescente, que salienta que o adolescente é um ser em desenvolvimento e que, nesse sentido, deve ser submetido às medidas socioeducativas. Essas medidas são compreendidas como ações educativas e não punitivas, mesmo a ação de internamento, e visam à colocação ou recolocação do jovem no trabalho, na escola e na família, sempre acompanhado por uma equipe de técnicos.

Entende-se o desespero da sociedade que vê dia a dia seu espaço confiscado pela violência nas ruas e pelas invasões de suas casas. Tal estado de ânimo nos leva a buscar alternativas à violência. A imprensa aponta a diminuição da maioridade penal como uma alternativa eficaz para esse grave problema, acreditando que as medidas socioeducativas adotadas pelo ECA são incapazes de combater a criminalidade juvenil por serem pouco severas, favorecendo a sensação de impunidade. No entanto, a alternativa apresentada pelo Senado Federal - encarceramento do adolescente de 16 anos pelo sistema penal vigente -, além de ser equivocada por não ter base nos dados científicos, visa tão-somente punir com rigor o adolescente infrator. A passagem em instituições prisionais não tem caráter educativo, capaz de inibir o crime futuro, mas sim, se configura por ambiente propício para o desenvolvimento de comportamentos e da identidade infratora, aumentando 
significativamente a rede de contatos criminosos do detento, de tal forma que, após o encarceramento, o indivíduo estará mais preparado do que antes para exercer as atividades infratoras.

A alternativa à violência juvenil está na ampliação das atividades do sistema educacional que possam acolher e atender adolescentes em situação de risco, dando-lhes reforço escolar, atividades lúdicas e culturais, além de apoio emocional capaz de aumentar sua auto-estima, o que inibiria, por esse recurso, seu ingresso em gangs e atividades infratoras. Está, ainda, nos atendimentos às famílias em situação de risco, que poderão ser em nível preventivo (orientação), remediativo (treinamento) ou terapêutico (terapia). Essas medidas necessitam de apoio governamental imediato. A total reformulação do sistema de internação de adolescentes em conflito com a Lei, que permita o pleno funcionamento das medidas socioeducativas preconizadas pelo ECA, é urgente. Mudar a legislação para que adolescentes de 16 a 18 anos cumpram penas no sistema prisional sem perspectiva de receber atenção psicossocial adequada não é a solução.

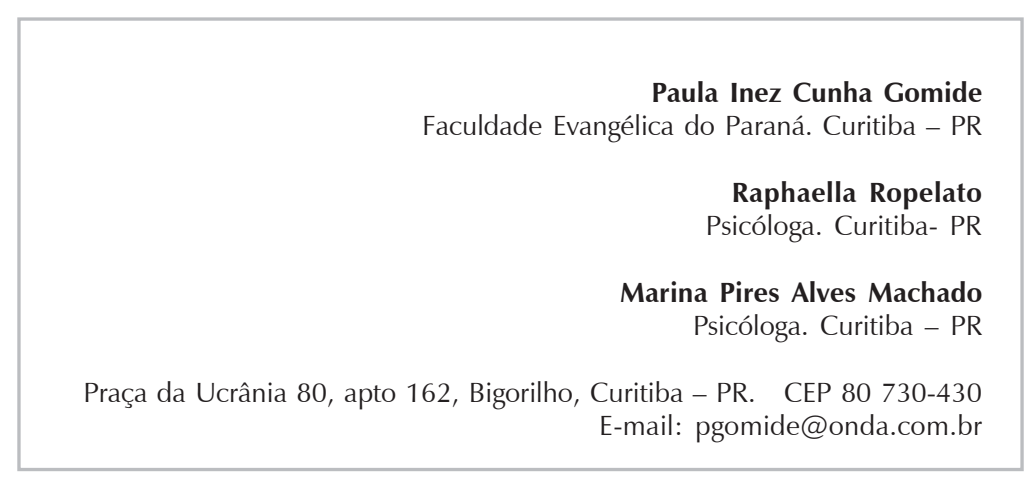


AGÊNCIA DO SENADO (2003) Analisa a redução da maioridade penal para 16 anos. Disponível: www.senado.gov.br/agencia/noticia/ 2003/not106.asp

ALTOÉ, S. Os Processos Disciplinares nos Internatos de Menores. Espaço: Cadernos de Cultura USU, Rio de Janeiro, v.11, pp. 39-51, 1985.

AGÊNCIA NACIONAL DE DIREITOS DA INFÂNCIA (1999) Disponível: www.andi.org.br/boletins/2003/ma

ARAUJO, U.F. Conto de Escola: a Vergonha como um Regulador Moral. Editora Moderna. 1999.

ARRUDA, R.S.V. Pequenos Bandidos. São Paulo: Global Editora, 1983.

BAETA, A.M.B. Estudo de Instituições de Atendimentos ao Menor Desassistido na Perspectiva de seus Objetivos, Metodologia, Recursos Humanos e da Possibilidade de Integração desse Menor no Mercado de Trabalho. Espaç̧o: Cadernos de Cultura USU, Rio de Janeiro, v. 4, pp. 65-78, 1982 .

BERRI, G. Programa de Intervenção em Práticas Parentais para Mães de Adolescentes em Conflito com a Lei. Dissertação de Mestrado defendida no Programa de Psicologia da Infância e da Adolescência da UFPR, 2004

BIERREMBACH, M. I; SADER, E. e FIGUEIREDO, C.P. Fogo no Pavilhão: uma Proposta de Liberdade para o Menor. São Paulo: Editora Brasiliense, 1987.

BORRING, N. (2003). Redução da maioridade penal no novo Código Civil. Jornal da Segurança (on line), edição 77. Disponível: http://www.segurancala.com.br/noticias/arquivo/015.htm.
CAMPOS, A.V.D.S. Menor Institucionalizado: um Desafio para a Sociedade (Atitudes, Aspirações e Problemas para sua Reintegração à Sociedade). Tese de Doutorado em Psicologia. Instituto de Psicologia da Universidade de São Paulo, 1981.

CARVALHO, M.C.N. E GOMIDE, PI.C. Práticas Educativas Parentais em Famílias de Adolescentes em Conflito com a Lei. Estudos de Psicologia PUC-CAMPINAS,vol. 22, no. 3, pp. 263-276, 2005.

COELHO JUNIOR, L.L. Uso Potencial de Drogas em Estudantes do Ensino Médio: suas Correlações com as Prioridades Axiológicas. Dissertação de Mestrado em Psicologia Social. Universidade Federal da Paraíba, João Pessoa, PB, 2001.

CONSELHO FEDERAL DE PSICOLOGIA. Resolução CFP 002/2001 Altera e regulamenta a resolução CFP n. 14/2000, que institui o título profissional de especialista em Psicologia e o respectivo registro nos conselhos regionais - Anexo I, Brasília, DF, 2001.

COMTE-SPONVILLE, A. Pequeno Tratado das Grandes Virtudes. São Paulo: Martins Fontes. 2000.

CONTE, F.C.S. Pesquisa e Intervenção Clínica em Comportamento Delinqüente numa Comunidade Pobre. Tese de Doutorado em Psicologia. Instituto de Psicologia da Universidade de São Paulo, 1996.

CUNEO, M. R. Inimputabilidade não é Impunidade. Derrube esse Mito. Diga não à Redução da Idade Penal. Revista Igualdade, v. 9 n.31, pp.22-37, 2001.

EDMUNDO, L. P. Instituições: Escola da Marginalidade? São Paulo: Cortez, 1987

FELDMAN, M.P. Comportamento Criminoso: uma Análise Psicológica. Rio de Janeiro: Zahar, 1977. 
FORMIGA, N.S. E GOUVEIA, V.V. Valores Humanos e Condutas Antisociais e Delitivas. Psicologia: Teoria e Prática, São Paulo, 7(2), pp. 134-170, 2005.

GOMIDE, P.I.C. Menor Infrator: a Caminho de um Novo Tempo. Curitiba: Juruá, 1998.

GOMIDE, P.I.C. Estilo Parental e Comportamento Anti-social. In: Del Prette, A. e Del Prette, Z. (orgs) Habilidades Sociais, Desenvolvimento e Aprendizagem: Questões Conceituais, Avaliação e Intervenção. Campinas: Alínea, 2003, pp. 21-60.

GOMIDE, PI.C. Pais Presentes, Pais Ausentes: Regras e Limites. Petrópolis: Vozes, 2004.

GOMIDE, PI.C; SALVO, C.G.; PINHEIRO, D. ESABBAG, G. Correlação entre Práticas Educativas, Depressão, Stress e Habilidades Sociais. Revista PsicoUSF, vol. 10, no. 2, julho/dezembro, pp. 169-178, 2005.

GOMIDE, P.I.C. Inventário de Estilo Parental: Modelos Teóricos, Manuais de Aplicação, Apuração e Interpretação. Petrópolis:Editora Vozes, 2006.

GUSMÃO, E.E.; JESUS, G. R.; GOUVEIA, V.V.; JUNIOR, J.N. e QUEIROGA, F. Interdependência Social e Orientações Valorativas em Adolescentes. Revista Psico, Porto Alegre, vol. 32, pp. 23-37, 2001.

KASDIN, A.E.; BUELA-CASAL, G. Conducta Anti-social: Evaluación, Tratamiento y Prevención em la Infancia y Adolescencia. Madrid: Pirâmide, 1977.

KURTINES, W.M. EGEWIRTZ, J.L. Handbook of Moral Behavior and Development, vol. 1,2,3. New Jersey: Laurence Erbaum Associates, Publishers, 1991.

LA TAILLE, Y. Vergonha: a Ferida Moral. Editora Vozes, São Paulo, 2004

LUPPI, C.A. Malditos Frutos de Nosso Ventre. São Paulo: Ícone, 1987.

MINISTÉRIO DA JUSTIÇA \& IPEA. Mapeamento Nacional de Situação do Atendimento dos Adolescentes em Cumprimento de Medidas Socioeducativas. Secretaria de Estado dos Direitos Humanos e Departamento da Criança e do Adolescente, 2002.

MONTAGU, A. Tocar: o Significado Humano da Pele. São Paulo: Summus, 1988

NETO, G.G.G. O Adolescente Autor de Ato Infracional frente aos Princípios Garantistas do Estatuto da Criança e do Adolescente. Revista Igualdade, Curitba, v. 20, pp.1-10, 1998

NETO, O.S.S.M. e GRILLO, V.T.M. Recurso de Apelação no 95.0000029-6, de Nova Londrina. Revista Igualdade, Curitiba,v. 9, pp.73-81, 1995.

NURCO, D. e LERNER, M. Vulnerability to Narcotic Addiction: Family Structure and Funcioning. Journal of Dug Issues, v. 26, pp.10071095, 1996.

PATTERSON, G., REID, J. e DISHION, T. Antisocial Boys. EUA: Castalia, 1992.

PETRAITIS, J.; FLAY, B. R. E MILLER, T.Q.. Reviewing Theories of Adolescent Substance Use: Organizing Pieces in the Puzzle. Psychological Bulletin, v. 117, pp. 67-86, 1995.
PINHEIRO, A.A.A. Falando de um Brasileiro: o Menor. Revista de Psicologia, vol.3, pp. 75-78, 1985.

PINHEIRO, D, P.N. Estilo Parental: uma Análise Qualitativa. Dissertação de Mestrado defendida no Programa de Psicologia da Infância e da Adolescência da UFPR, 2003.

PRUST, W, L. e GOMIDE, P.I.C. Análise de Discursos-síntese de Comportamento Moral em Famílias de Risco e de Não-risco. Psicologia: Reflexão e Crítica, no prelo

PRUST, W, L. E GOMIDE, PI.C.Relação entre Comportamento Moral dos Pais e dos Filhos Adolescentes. Psicologia: Teoria e Pesquisa, no prelo.

RIBEIRO, I. e BARBOSA, M.L.V. (orgs). Menor e Sociedade Brasileira: Análises, Programas Institucionais, Experiências. São Paulo: Loyola, 1987.

RIZZINI, I. A Internação de Crianças em Estabelecimentos de Menores: Alternativa ou Incentivo ao Abandono? Espaço: Cadernos de Cultura USU, Rio de Janeiro, v. 11, pp. 17-38, 1985.

ROCHA, L.C. Vidas Presas: uma Tentativa de Compreender a Tragédia da Criminalidade junto às suas Personagens Oprimidas. Dissertação de Mestrado em Psicologia. Instituto de Psicologia da Universidade de São Paulo, São Paulo, 1984.

ROMERO, E.; SOBRAL, J.; LUEGO, M.A. EMARZOA, J.A.. Values and Antisocial Behavior among Spanish Adolescents. The Journal of Genetic Psychology, v. 162, pp. 20-40, 2001.

SANSON, M.C.M. Considerações Teórico-práticas sobre a Audiência de Apresentação de Adolescente Autor de Ato Infracional perante o Ministério Público: Finalidade e Condução. Revista Igualdade, v. 7, pp. 106-113,1999

SARAIVA, J.B.C. Direito Penal Juvenil: Adolescente e Ato Infracional: Garantias Processuais e Medidas Socioeducativas. 2a ed. Porto Alegre: Livraria do Advogado, 2002.

SIDMAN, M. Coerção e suas Implicações. Campinas: PSY II, 1995.

SILVA, R.S.G. Institucionalização e Desenvolvimento Psicológico da Criança. Tese de Doutorado em Psicologia. Instituto de Psicologia da Universidade de São Paulo, São Paulo, 1977.

SILVA, H. S. "Joça Pivete"- o Menor Violentado. São Paulo: Cone, 1987.

SUBCOMISSÃO DA CRIANÇA E DO ADOLESCENTE DA OAB/ PARANÁ - Brauner, M.C.C.; Carazzai, L.R.; Gomide, P.I.C; Pansini, M.F; Pinto, M.L. T. Marilú Ferreira, Tonin, M.M. Estatuto da Criança e do Adolescente - cinco anos depois. Revista Igualdade, v. 09, pp. 32-49, 1995

TAMAYO, A.; NICARETTA, M.; RIBEIRO, R. E BARBOSA, L.P.G. Prioridades Axiológicas y Consumo de Drogas. Acta Psiquiátrica y Psicológica de la América Latina, v. 4, pp. 300-307, 1995.

VILLELA, M.C.L. Proposta de uma Prática Pedagógica para Menores Autores de Infração Penal Institucionalizados - uma Pedagogia do Trabalho. Dissertação de Mestrado em Psicologia. Programa de Supervisão e Currículo da PUC-SP, São Paulo, 1983.

VIOLANTE, M.L. O Dilema do Decente Malandro. São Paulo: Cortez, 1982. 